\title{
Hierarchical Life-Cycle Design of Concrete Structures
}

\author{
Zhujun Wang, Weiliang Jin, and Ju Chen \\ Department of Civil Engineering, Zhejiang University
}

\begin{abstract}
Concrete structures' service life lasts decades. In order to deal with all the probable degradations and deteriorations in the whole life span, the concept of concrete structures' Life-Cycle Design was introduced into China in the 1980s. However, until this day, Life-Cycle Design is still more of a concept to most structure designers and engineers, rather than a practical method. This paper provides a hierarchical method for concrete structures' Life-Cycle Design, in which the design process is divided into five levels. Safety should be the fundamental requirements for all concrete structures, so as to guarantee a reliable quality. For structures located in severe environments, durability design is necessary so as to ensure the designed service life. Further, when specific economic requirements are set for concrete structures, life-cycle cost (LCC) should be considered carefully in selecting the optimal scheme. Besides, those concrete structures designed to be environmental-friendly should also take into account the specific environmental assessment criteria. Nowadays, user-friendly schemes have attracted increasing attention too; therefore, customers' demands should also be fully involved in the design process. Considering all the design levels mentioned above, diverse designing criteria are provided accordingly. This paper also uses a road bridge member which exposed to chloride attack in marine environment as an example to illustrate this hierarchical design method. Using the life-cycle-based hierarchical design method, a probable scheme that is safe, durable, economic, environmental friendly, and user friendly is provided.
\end{abstract}

\section{INTRODUCTION}

Increasing attention has been paid on the environmental implications of human activities, including the consumed resources and emitted wastes. Human activities around the world emit as much as $7 \times 10^{9} t$ carbon dioxide every year. And according to IPCC, construction industry is responsible for $36 \%$ of the carbon dioxide emission and $40 \%$ of the energy consumption in global industries. To cope with increasingly severe environmental problems in the process of manufacturing and construction, environmentally conscious design, assessment and management methodologies aiming at the whole lifespan of products are required.

On the other hand, concrete structures' service life lasts decades, during which they are supposed to bear loads, actions, environmental influences and natural hazards, as well as to provide reliable space for specified use. In order to deal with all the probable degradations and deteriorations in the designed service life, and to meet the projects' lifecycle requirements and customers' diverse needs, the concept of structures' Life-Cycle Design (LCD) was promoted and introduced into China (Hu, 2009; Zhong \& Jin, 2009).

LCD was first emerged in military industry and manufacturing industry. LCD seeks to minimize the environmental influences of raw materials and manufacturing process, also the costs of manufacturers and customers, while improve the performance and maximize the contribution to society of products (Alting, 1995; Ishii, 1995). In this case, LCD is an integrated design system with multiobjective and multi-criteria, which, in the course of development, combined the views of Design for Manufacturability (DFM), Design for Assembly (DFA), Design for Serviceability (DFS), Design for Environment (DFE), Design for Product Retirement (DFPR), Failure Modes and Effect Analysis (FMEA), etc. (Ishii, 1995). Kota and Chakrabarti (2014) established a holistic framework for product LCD, which contains six aspects, namely, activities, criteria, life cycle phases, outcomes, design stages, and product structure. At a certain design stage, designers conduct an activity on an outcome based on criteria for a life cycle phase of a component of the product structure. Lu, Gu, and Spiewak (2011) proposed a framework towards product sustainable design considering the optimization of functional, economic and environmental performance of product.

In the domain of building industry, Life-Cycle Assessment (LCA) and Life-Cycle Cost (LCC) analysis are also high-frequency words in researches, which are widely studied and applied. However, until this day, LCD is still more of a concept to most structure designers and engineers, rather than a formal practical method. Bergmeister (2014) suggested that real application of LCD on important structures are still 
quite limited, despite the huge improvement in design optimization, so he applied LCD to the Brenner Base Tunnel project using a gradient limit state approach. LCD is an interdisciplinary design system that contains the knowledge of not only civil engineering, but also the dimensions that were overlooked in the past, such as power source, system management, environment resources, economics, etc., which makes the traditional approach nearly impossible to fulfill all the requirements (Mora, Bitsuamlak, \& Horvat, 2011).

Studies on various aspects of LCD have been carried out in the past few years. Hassan, Al Maazmi, Al Hadhrami, and Al Hosani (2015) suggested that discrete event simulation is a LCD tool that could optimize resource distribution and get a more efficient system. Kim, Kara, and Kayis (2014) assessed the economic and environmental influences of product LCD in the angle of technology improvement, suggesting that new technology would offer improved product performance with less environmental burden. Furuta, Kameda, Nakahara, Takahashi, and Frangopol (2006) considered LCC, safety level and service life in the formulation of optimization of maintenance of bridges. Basbagill, Flager, Lepech, and Fischer (2013) applied LCA in the early stage of LCD to identify the environmental importance of decision making in that phase. Frangopol, Kong, and Gharaibeh (2001), Biondini and Frangopol (2014) studied the life-cycle performance and management of bridge structures based on reliability and uncertainty. However, few research focus on the overall framework and practical application of LCD in structural engineering.

Evaluating existing structures under LCA approach is quite common, while the design of new structures in a life-cycle way is still unfamiliar to the designers. Structure designers usually took a lot of time wondering, what is the most critical and fundamental objective and criterion among all the designing requirements, or where to begin with. And more often, designers would fail to cover all the objectives and criteria which are necessary to LCD in the designing process, or rather choose to turn to traditional designing methods for conveniences.

In the context of the abovementioned problems, the establishment of a logical and well-ordered LCD method is quite necessary.

\section{LCD OBJECTIVE SYSTEM}

The LCD method is a supplement and extension to the traditional designing method, which means that the LCD system is a combination of traditional and innovative objectives and criteria, from both construction industry and non-construction industries. The objective system of LCD theory contains two major components (Jin \& Zhong, 2012):

- Core objectives, including performances, service life time, as well as economic efficiency of structures (or cost);

- Green objectives, containing environmental evaluation, evaluation from users and society, and sustainability evaluation.

Core objectives aims at accomplishing a safe, reliable, usable and durable structure, which are the essential conditions to any structural project and represent the realistic thinking in the structure designing process. While the establishment of the green objectives is out of a more rational and philosophical consideration, which deal with the correlations between structures and its surroundings, including human beings, environments, and regional or global ecologies. The following pyramid shows the hierarchical relationships among these designing objectives (Hu, 2009; Zhang \& Cheng, 2011):

As can be seen from the figure above, with core objectives as the foundation of designing and the green objectives as the representation of the concerns toward human and nature, structures' designing objectives could be well organized

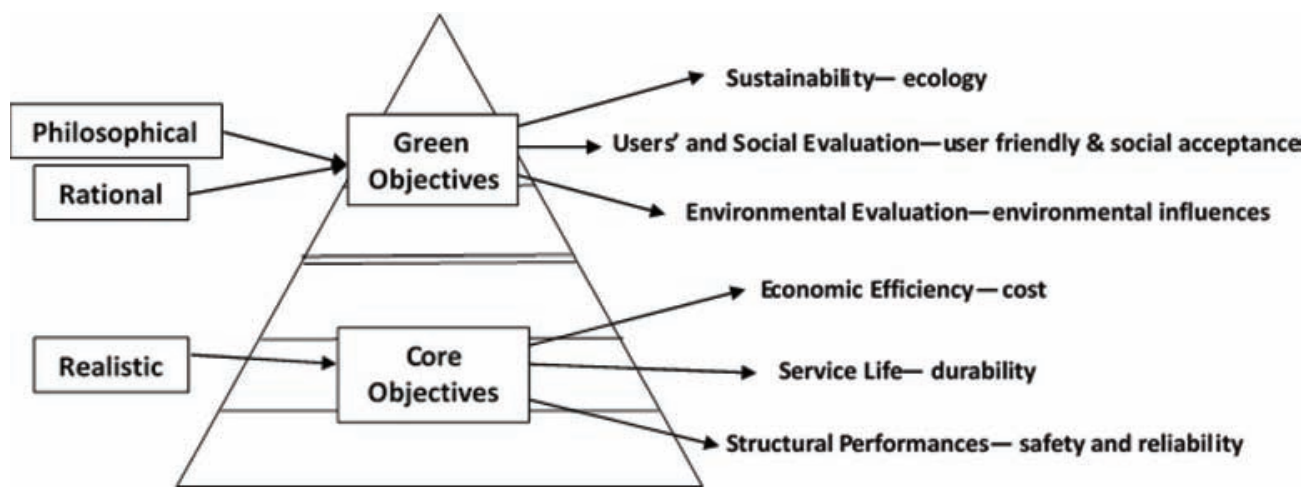

Figure 1. Hierarchical relationships of LCD objectives. 
according to their necessity and significance. And the designing process could also proceed following the exact same order.

Safety and reliability design should be the first step in the LCD of concrete structures, which could define the value ranges for various designing criteria corresponding to different initial choices.

Durability design is meant to ensure an adequate service life time, whose results could be used to revise or supplement the initial schemes, or narrow the value ran ges of designing criteria.

Economic evaluation takes account of concrete structures' LCC, including construction, tests, inspections, monitoring, operation, maintenance, repair/rehabilitation (both direct and indirect), and dismantlement cost. This part of designing process focuses on choosing economic schemes that are beneficial to all the shareholders and to society.

Environmental evaluation constrains structures' influences on environment by setting up criteria such as harmful emissions, water efficiency, solid wastes, etc. By setting a limitation of $\mathrm{CO}_{2}$ emissions, lowcarbon structures could be selected from all possible schemes.

Evaluation from users and society copes with the lifecycle structural influences that exerted on users and society. Usually, this part is used to assess whether an existing structure or a designed scheme is userfriendly enough. So it's arranged at the latter part of the designing process in order to select schemes with higher user-friendly scores. The same is applicable to the sustainability evaluation as well.

\section{HIERARCHICAL LCD METHOD}

According to the hierarchical relationship mentioned above, the LCD of concrete structures could be divided into five levels:

\subsection{Level 1 - safety and reliability design}

The partial factor design method (GB50009-2001) is currently being used, which could provide the structural components with adequate load-bearing capacity and ensure an adequate reliability level at the same time, as shown in Formula (1).

$$
R_{d}=\gamma_{0}\left(\gamma_{G} S_{G K}+\gamma_{Q 1} S_{Q 1 k}+\sum_{i=2}^{n} \gamma_{Q i} \psi_{c i} S_{Q i k}\right)
$$

where $R_{d}$ is design value of resistance, $\gamma_{0}$ coefficient for importance of structure, $\gamma_{G}$ coefficient for permanent loadings, $\gamma_{Q 1}$ coefficient for dominating variable loadings, $\gamma_{Q i}$ coefficient for other variable loadings, $\psi_{Q i}$ combination coefficient for other variable loadings, $S_{G k}$ standard value of permanent loadings, $S_{Q 1 k}$ standard value of dominating variable loadings, and $S_{\text {Qik }}$ standard value of other variable loadings.

For structures that are likely to be subjected to special actions, such as dynamic loadings, repeated loadings, wind, and seismic loadings, designers should execute specific designing process correspondingly (ISO23942015).

Codes and standards for design of concrete structures could also be applied at calculating the strength, stiffness, stability, and serviceability (e.g., crack width and deflection).

When the loadings the structure is supposed to bear are well defined, the structural format, cross-sectional shape, geometric dimensions, material properties, and admixtures of the structure are the essential factors in the designing process, whose different combinations could lead to different designing results and engineering quantities.

In the following designing levels, more constraints should be applied on the designing results received above, so as to narrow the scope of choices and get to the optimal scheme.

\subsection{Level 2 - durability design}

For structures located in aggressive environments, codes and standards provide detailed structural requirements, such as the thickness of concrete layer, crack-controlling requirements, maintenance requirements, drainage requirements, etc., corresponding to different types and levels of environment actions.

When the location of a certain structure is specified, the environmental actions (type and level) imposed upon it would also be clearly defined. The structural requirements mentioned above are useful here in sifting out the schemes that are not expected to be durable enough.

Besides, various durability techniques are also helpful in promoting structures' resistance to environmental actions. For example, epoxy coating for rebar and concrete could block the invasion of chloride ions, and several electrochemical methods could also extend the lifespan of concrete structures suffered in ion intrusion. Once we knew the detailed information about these durability techniques, such as their service conditions, effects, durations, side-effects, and costs, they could be used and arranged reasonably in the designing schemes.

On the basis of fulfilling the detailed structural requirements, the cooperation of durability techniques could be used to prolong the structures' service life further. Different combinations of these techniques 
would add up to different total LCC, which is one of the major issues on all the stakeholders' (users, investors, governments, societies, etc.) mind. In light of this, the most economic schemes would cater to the stakeholders' favor.

\subsection{Level 3 - economic evaluation}

LCC is a comprehensive criterion on judging the economic efficiency of a structural project. It contains the costs of not only construction stage but also operation, maintenance, repairmen/rehabilitation, and demolition. Decisions made in the designing stage would have significant impacts on structures' future costs. Studies showed that although only $5-7 \%$ of the LCC is attributed by the design stage, but the decisions made in this stage determine $70-80 \%$ of the future cost (Ramani et al., 2010). Whether the structure is safe, reliable, and durable enough makes a great difference in how much would it cost on the maintenance and repairmen in the future. Besides, within the duration of repairmen/ rehabilitation, indirect costs would be generated because of the loss of functions (Cho, Kim, Choi, \& Lee, 2003).

LCC models should be established for typical structures, such as residential buildings, commercial buildings, industrial structures, road, and bridges, etc., considering both direct and indirect costs that occur in the whole designed service life. The models could help to calculate the LCC, evaluate the cost of structures, or identify the most economic schemes for a certain structure.

Structures' LCC model could be described as Formula (2):

$$
\mathrm{LCC}=\mathrm{C}_{c}+\mathrm{C}_{m}+\mathrm{C}_{r}+\mathrm{C}_{d}
$$

where $C_{C}$, construction costs, including the cost of construction materials, construction works; $C_{m}$, maintenance costs, including the cost of daily operation and routine inspections; $C_{r}$, repairmen/rehabilitation costs, including the direct costs generated by repairmen works, and the indirect costs caused by loss of functions; and $C_{d}$, demolition costs, including the costs of tearing down the scrapped structure, disposing the construction wastes, and the recycling process.

The abovementioned three levels of designing process could obtain structure schemes that are safe, reliable, durable, and economic, which would cater to the needs of general projects. However, with more and more attentions focused on the environmental effects of concrete structures, the construction of environmental-friendly structures is becoming increasingly important.

\subsection{Level 4 - environmental evaluation}

The conception of Green Building runs through the whole life cycle of engineering structures, with different green design contents at different stages. To achieve Green Construction, the considerations of construction materials and construction process are necessary. Structures' life-cycle Green Indexes are composed of environmental evaluation index, social evaluation index, and sustainable development index (Liu \& Zhou, 2003; Roper \& Beard, 2006). International committees and councils have established various evaluation systems aiming at the assessment of structures' environmental effects and energy efficiency, such as LEED of USA, CASBEE of Japan, BREEAM of UK, etc. Concrete structures' influence on environment could be classified as solid wastes, harmful emissions, noises, light pollution, vegetation deterioration (Chen, $\mathrm{Su}, \& \mathrm{Li}, 2009$ ), etc., among which $\mathrm{CO}_{2}$ emission is a criterion of great importance.

Carbon emission factors are widely used in the theoretic calculation of products' Life-Cycle $\mathrm{CO}_{2}$ Emission (LCCE), considering the production of construction materials, the construction, operation, repairmen process, and the demolition and recycling of aged structures. Formula (3) describes the LCCE of a structure.

$$
\mathrm{LCCE}=C E_{M}+C E_{C}+C E_{\mathrm{O}}+C E_{R}+C E_{D}
$$

where $C E_{M}$, carbon emissions of material production, including the process of exploiting raw materials and fabrication; $C E_{C}$, carbon emissions of construction, including the process of transporting and the operation of construction machineries; $C E_{O}$, carbon emissions of operation, including the daily consumption of water, electricity, gas, and the routine inspections and tests; $C E_{R}$, carbon emissions of repairmen, including the materials used in repairmen and the operation of relevant machineries; and $C E_{D}$, carbon emissions of demolition, including the demolition process, transporting of construction wastes, and recycling of materials.

\subsection{Level 5 - evaluation from users and society}

Structures not only play the role as shelter spaces but also cast great influences on human beings' physical and mental health, including the conveniences and comforts, indoor environments, outdoor environments, light environment/pollution, etc. (LEED, CASBEE, BREEAM, and CCES) Codes for designing on these aspects are incomplete, for which project experiences are the major basis for users' and social evaluation.

After the theoretical description of the hierarchical LCD method, an example would be used to illustrate it in the following part of this paper. 


\section{ILLUSTRATING EXAMPLE}

A cap beam in a highway bridge, as Figure 2 shows, is used as the example to illustrate the hierarchical LCD method. Detailed information about the beam is listed below:

- The cap beam is made of reinforced concrete and is located in marine-atmosphere environment, approximately $12 \mathrm{~m}$ above the sea surface.

- There are three driveways and one pavement on the $15.5-\mathrm{m}$ deck.

- Forces are transferred from the deck to the cap beam through two bearings, the distance between which is $6.9 \mathrm{~m}$.

- The cap beam is held by two columns with the diameter of $1.3 \mathrm{~m}$ and whose center distance is $7.5 \mathrm{~m}$.

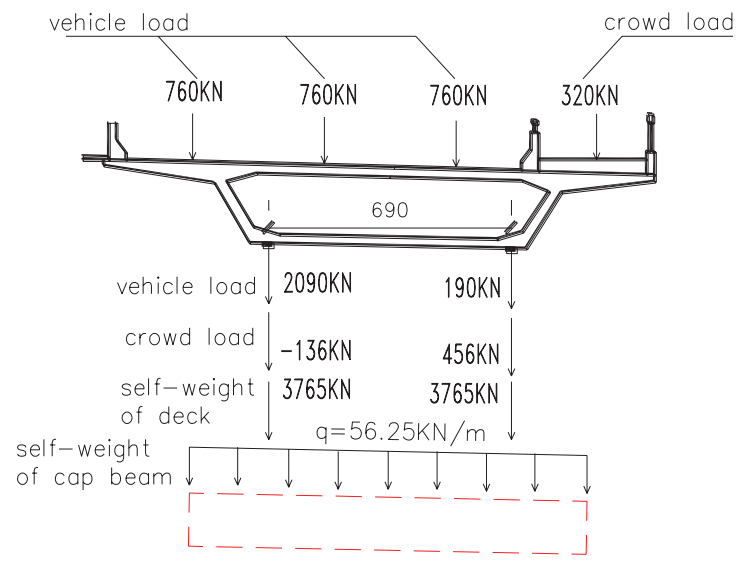

Figure 2. Loading conditions of the cap beam.

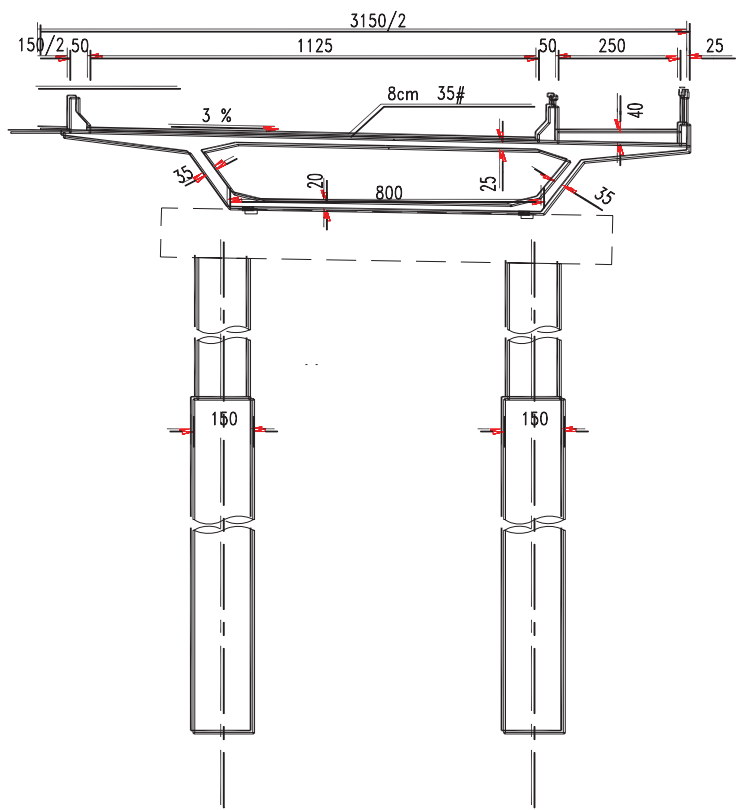

Figure 3. Illustrating example - the cap beam (the dashed box).
According to the predetermined conditions, it is reasonable to identify the main cross section of the cap beam as a $1.5 \mathrm{~m} \times 31.5 \mathrm{~m}$ rectangular, and the total length of it to be $15 \mathrm{~m}$ so that no tensile force would occur between the columns and the cap beam. So, the loadings imposed upon it and the uniformly distributed self-weigh could be summarized in Figure 3.

\subsection{Level 1}

Taking the seismic loadings and wind into account, and using PKPM and TSSD as tools, a number of designing schemes are proposed, with various structure form (I for fixed cross-section and I/ for variable cross-section), concrete strength level ( $i-\mathrm{C} 30$, ii-C40, iii-C50, and iv-C60), reinforcement strength level ( $A$ - HRB335, B - HRB400, and C - HRB500), and the thickness of concrete layers $(a-40 \mathrm{~mm}$, $b-50 \mathrm{~mm}, c-60 \mathrm{~mm}$, and $d-70 \mathrm{~mm}$ ).

According to the results of calculation, structure form and concrete cover thickness both appear to be unimportant indicators in this particular case, in terms of determining the arrangement of reinforcements, since the amount of reinforcements of this case is mainly dependent on the requirement of minimum reinforcement ratio.

However, considering the principles of reducing structural self-weight and the consumption of materials, variable cross-section seems to be a better choice. Detailed reinforcement arrangement is shown in Table1.

In Table 1, T, S, and B represent the top reinforcement, stirrup, and bottom reinforcement $\left(\mathrm{mm}^{2}\right)$, respectively. In the column of total material quantity $(m), L R Q$ and $S Q$ refers to the quantity of longitudinal reinforcement and stirrups, respectively. Moreover, by further optimization of reinforcement arrangements, the diameter of longitudinal reinforcement should be $25 \mathrm{~mm}$, and 10-mm diameter reinforcement is chosen as stirrups.

\subsection{Level 2}

According to GB/T 50476-2015 Code for Durability Design of Concrete Structures and CCES 01-2004 (2004) Guide to Durability Design and Construction of Concrete Structures, the cap beam is located in Heavy Salt Spray Environment classified as III-E environment, and requirements are raised to ensure the durability of the cap beam. On the basis of these requirements, the range of alternatives is narrowed down, from which the concrete level $i$ and $i i$, reinforcement level $A$, concrete cover thickness $a$ and $b$ are excluded. Moreover, additional durability strategies are mentioned to be beneficial in durability promotion, such as mineral admixtures, such as silica fume (SF), fly ash (FA), blast furnace slag (SL), and water reducer (WR), and durability promotion techniques, such as 
Table 1. Reinforcement arrangement and total material quantity of various schemes.

\begin{tabular}{|c|c|c|c|c|c|c|c|c|c|c|c|}
\hline \multirow[b]{3}{*}{ Scheme } & \multicolumn{11}{|c|}{ Position } \\
\hline & \multicolumn{3}{|c|}{ Cantilevers } & \multicolumn{3}{|c|}{ BP.s and LP.s } & \multicolumn{3}{|c|}{ Mid-span } & \multicolumn{2}{|c|}{$\begin{array}{l}\text { Total material } \\
\text { quantity }\end{array}$} \\
\hline & $\mathbf{T}$ & $\mathbf{S}$ & B & $\mathbf{T}$ & $\mathbf{S}$ & B & $\mathbf{T}$ & $\mathbf{S}$ & B & LRQ & SQ \\
\hline $\mathrm{i}-A$ & 4900 & 50 & 4900 & 7000 & 240 & 7000 & 0 & 240 & 7000 & 369.7 & 1021.4 \\
\hline $\mathrm{i}-B$ & 4083 & 42 & 4083 & 5833 & 200 & 5833 & 0 & 200 & 5833 & 307.2 & 1021.4 \\
\hline $\mathrm{i}-\mathrm{C}$ & 3380 & 35 & 3380 & 4828 & 166 & 4828 & 0 & 166 & 4828 & 262.1 & 1021.4 \\
\hline $\mathrm{ii}-A$ & 5800 & 50 & 5800 & 8400 & 290 & 8400 & 0 & 290 & 8400 & 421.9 & 1021.4 \\
\hline $\mathrm{ii}-B$ & 4833 & 42 & 4833 & 7000 & 242 & 7000 & 0 & 242 & 7000 & 370.8 & 1021.4 \\
\hline ii- $C$ & 4000 & 35 & 4000 & 5794 & 200 & 5794 & 0 & 200 & 5794 & 315.6 & 1021.4 \\
\hline iii- $A$ & 6400 & 50 & 6400 & 9200 & 320 & 9200 & 0 & 320 & 9200 & 454.2 & 1021.4 \\
\hline $\mathrm{iii}-B$ & 5334 & 42 & 5334 & 7667 & 267 & 7667 & 0 & 267 & 7667 & 397.0 & 1021.4 \\
\hline iii-C & 4415 & 35 & 4415 & 6346 & 221 & 6346 & 0 & 221 & 6346 & 336.2 & 1021.4 \\
\hline iv $-A$ & 6900 & 50 & 6900 & 10000 & 340 & 10000 & 0 & 340 & 10000 & 509.2 & 1143.2 \\
\hline iv- $B$ & 5750 & 42 & 5750 & 8384 & 284 & 8384 & 0 & 284 & 8384 & 441.9 & 1021.4 \\
\hline iv- $C$ & 4760 & 35 & 4760 & 6940 & 235 & 6940 & 0 & 235 & 6940 & 383.6 & 1021.4 \\
\hline
\end{tabular}

epoxy-coated reinforcement (ECR), epoxy coating for concrete (ECC), saline soakage for concrete (SSC), electrochemical chloride extraction (ECE), and bidirectional electro-migration (BE).

Chloride intrusion-induced corrosion is the main durability problem for concrete structures located in marine environment. The deterioration process of structure components could be divided into four stages, namely, the intrusion stage, incubation stage, cracking stage, and degradation stage. Usually, the appearance of cracking is considered the durability limit state and thus the time point of cracking the end of structural durability lifetime (Teplý, Vořechovská, \& Keršner, 2010). So, the durability lifetime of chloride intruded concrete structures could be described by Formula (4).

$$
T_{D}=T_{0}+T_{\text {cr }}
$$

where $T_{D}$ durability lifetime of structures, $T_{0}$ time point of depassivation, and $T_{c r}$ time point of cracking, also the symbol of durability limit state.

With the help of durability design, users and owners could choose the durability promotion methods as needed. If, for example, the project contract requires a durability lifetime of more than 50 years, then nearly half of the schemes listed above would be excluded, and Table 2 shows the choices still available in ascending order.

As can be indicated from the results, raising the thickness of concrete cover could be an easy and effective way to promote structures' durability. With 10-mm thicker concrete cover, the durability lifetime could be prolonged for 5-6 years, in this particular case. Neither the mineral admixtures nor the durability techniques, when using alone, are powerful enough to resist the chloride penetration for as long as 50 years. However, silica fume and the compound of fly ash and slag still show outstanding effects among mineral admixtures, so do the electrochemical methods among durability techniques. And the combination of outstanding mineral admixtures and durability techniques makes highly effective durability promotion measures.

Since the cap beam in our case requires a designed service life for at least 100 years, none of the durability schemes listed in Table 2 are qualified enough. So, durability techniques are required to be executed repeatedly in the operation stage, such as the coatings for concrete and the electrochemical methods.

\subsection{Level 3}

In order to select more economic schemes out of the abovementioned abundant choices, unit cost of construction materials, admixtures, and durability techniques are critical criteria in the assessment.

In order to maintain the durability of structure for at least 100 years, durability techniques are required to perform repeatedly.

From the analysis results, following conclusions could be drawn.

The deviation of direct cost between reinforcement HRB400 and HRB500 is so little that it can be neglected. In most cases, reinforcement with higher strength would have a relatively higher economic efficiency.

Since various schemes contribute to different durability lifetime, the comparison between schemes should 
Table 2. Schemes with durability lifetime longer than 50 years.

\begin{tabular}{|c|c|c|c|c|c|}
\hline Schemes & $\begin{array}{l}\text { Durability } \\
\text { lifetime }\end{array}$ & Schemes & $\begin{array}{l}\text { Durability } \\
\text { lifetime }\end{array}$ & Schemes & $\begin{array}{c}\text { Durability } \\
\text { lifetime }\end{array}$ \\
\hline $\mathrm{iii}-d-(\mathrm{FA}+\mathrm{SL})+\mathrm{ECC}$ & 50.2 & iv-c- $-(E C R+S S C)$ & 55.6 & $i v-c-S F+(E C R+S S C)$ & 61.3 \\
\hline iii- $d-$ SF-ECE & 50.3 & $\mathrm{iii}-c-\mathrm{FA} / \mathrm{SL}-(\mathrm{ECR}+\mathrm{SSC})$ & 55.9 & $\mathrm{iv}-d-(\mathrm{ECR}+\mathrm{SSC})$ & 61.4 \\
\hline $\mathrm{iii}-c-(F A+S L)+E C E$ & 50.5 & iv- $d$ - SF-ECE & 55.9 & $\mathrm{iii}-d-\mathrm{FA} / \mathrm{SL}-(\mathrm{ECR}+\mathrm{SSC})$ & 61.9 \\
\hline $\mathrm{iv}-\mathrm{c}-(\mathrm{ECR}+\mathrm{ECC})$ & 50.6 & $i v-c-(F A+S L)+E C E$ & 56.2 & $i v-c-(F A+S L)+(E C R+E C C)$ & 63.9 \\
\hline$i i i-c-(F A+S L)+E C R$ & 50.7 & $i v-c-S F+(E C R+E C C)$ & 56.3 & $\mathrm{iv}-d-\mathrm{SF}+(\mathrm{ECR}+\mathrm{ECC})$ & 64.3 \\
\hline iii-c - FA/SL - (ECR + ECC) & 50.9 & iv- $d-(E C R+E C C)$ & 56.4 & $\mathrm{iv}-d-(\mathrm{FA}+\mathrm{SL})-\mathrm{ECR}$ & 64.6 \\
\hline iii- $d$ - SF-ECC & 51 & iii- $d-F A / S L-(E C R+E C C)$ & 56.9 & $i v-d-F A / S L+(E C R+S S C)$ & 64.6 \\
\hline iv-d-FA/SL-BE & 52.1 & $\mathrm{iv}-c-\mathrm{FA} / \mathrm{SL}+(\mathrm{ECR}+\mathrm{SSC})$ & 57.9 & $\mathrm{iii}-C-(F A+S L)+(E C R+S S C)$ & 65.7 \\
\hline$i v-c-F A / S L+(E C R+E C C)$ & 52.9 & iii-c $-S F-(E C R+S S C)$ & 58.9 & iii- $d-S F-(E C R+S S C)$ & 66 \\
\hline $\mathrm{iii}-c-(E C R+S S C)$ & 53.8 & $\mathrm{iii}-d-(\mathrm{ECR}+\mathrm{SSC})$ & 59.1 & $\mathrm{iii}-d-(\mathrm{FA}+\mathrm{SL})+\mathrm{ECE}$ & 67.2 \\
\hline iii-C - SF - (ECR + ECC) & 53.9 & iv- $d-(\mathrm{FA}+\mathrm{SL})-\mathrm{SSC}$ & 59.6 & $i v-c-(F A+S L)+(E C R+S S C)$ & 68.9 \\
\hline$i v-c-(F A+S L)+E C R$ & 53.9 & iv- $d-\mathrm{FA} / \mathrm{SL}+(\mathrm{ECR}+\mathrm{ECC})$ & 59.6 & $i v-d-S F+(E C R+S S C)$ & 69.3 \\
\hline $\mathrm{iii}-d-(\mathrm{ECR}+\mathrm{ECC})$ & 54.1 & $\mathrm{iii}-d-(\mathrm{FA}+\mathrm{SL})+\mathrm{ECR}$ & 60.2 & $\mathrm{iii}-d-(\mathrm{FA}+\mathrm{SL})+\mathrm{BE}$ & 72.2 \\
\hline $\mathrm{iv}-d-(\mathrm{FA}+\mathrm{SL})-\mathrm{ECC}$ & 54.6 & $\mathrm{iii}-c-(F A+S L)+(E C R+E C C)$ & 60.7 & $\mathrm{iv}-d-(\mathrm{FA}+\mathrm{SL})-(\mathrm{ECR}+\mathrm{ECC})$ & 74.6 \\
\hline $\mathrm{iii}-d-(\mathrm{FA}+\mathrm{SL})+\mathrm{SSC}$ & 55.2 & iv- $d-S F-B E$ & 60.9 & $\mathrm{iv}-d-(\mathrm{FA}+\mathrm{SL})-\mathrm{ECE}$ & 74.9 \\
\hline iii- $d-S F-B E$ & 55.3 & iii- $d-S F-(E C R+E C C)$ & 61 & $\mathrm{iv}-d-(\mathrm{FA}+\mathrm{SL})-(\mathrm{ECR}+\mathrm{SSC})$ & 79.6 \\
\hline $\mathrm{iii}-\mathrm{C}-(\mathrm{FA}+\mathrm{SL})+\mathrm{BE}$ & 55.5 & $i v-c-(F A+S L)+B E$ & 61.2 & $\mathrm{iv}-d-(\mathrm{FA}+\mathrm{SL})-\mathrm{BE}$ & 79.9 \\
\hline
\end{tabular}

share a common basis, which is the direct annual cost of structure.

Results show that nearly all the schemes are required to combine mineral admixtures, which is the most basic and effective way to promote concrete durability. On the other hand, the repeatedly painted coating of concrete appears to be the most economic durability measure, which also performs quite well when combined with epoxy coating for reinforcement. And the electrochemical techniques, with same durability effects, demand much higher investments.

The effect of FA and SL as single admixture is similar, so do their unit costs. But the consumption of FA is smaller than $S L$ when aiming at same durable effect, which means the employment of FA is more economic.

Most of the cases hold the direct annual cost around $¥ 250-500$ /year, and the direct annual cost of a small number of schemes is extremely huge. Suppose that the users and owners set the standard of direct annual cost to be under $¥ 350$ /year, more than half of the schemes would be sifted out.

To our cases, great user cost would happen to the schemes using electrochemical durability techniques. Electrochemical techniques need to wrap up the component and soak it into the electrolyte for energization day and night for weeks, which requires the component to hold steady without big movement or vibration. So, when performing electrochemical techniques, at least half of the driveway should be closed and the traffic capacity would be influenced, at least 8 weeks for ECE and 18 weeks for BE. However, the execution of coating painting have no such strict limitation, since the painting could take place even when the structure is on service and no influence would be cast down to the traffic.

After the analysis of indirect costs, even bigger advantage is given to the coatings of concrete, compared to electrochemical measures. In light of this, the schemes applying electrochemical measures are given up completely, and more attention would be paid to the schemes with direct annual cost under $¥ 350$ /year. Since the painting construction scarcely trigger any indirect cost, we reckon that the total LCC equals to the direct cost, which are listed in Table 3.

\subsection{Level 4}

In the environmental evaluation part, main focus would be paid on the comparison of the $\mathrm{CO}_{2}$ emission of each scheme. Carbon emission factors are widely used in the theoretical calculation of products' LCCE.

In the cases of bridges, the emission of operation stage is relatively fixed, which mainly contains the electricity for illumination and routine inspections, and the only variable in it is the emission of different durability maintenance schemes (material and construction). The carbon emission of different schemes in construction stage is also quite similar, since the materials and construction procedure of concrete bridges are relatively changeless. 
Table 3. Schemes with annual cost under $¥ 350 /$ year.

\begin{tabular}{|c|c|c|c|}
\hline Schemes & Durability lifetime (years) & Total LCC (¥) & Annual cost (¥/year) \\
\hline iv- $d-(\mathrm{FA}+\mathrm{SL})-4^{*} \mathrm{SSC}$ & 104.6 & 29368.79 & 280.77 \\
\hline $\mathrm{iv}-d-\mathrm{FA} / \mathrm{SL}+(\mathrm{ECR}+\mathrm{SSC})+3^{*} \mathrm{SSC}$ & 109.6 & 35395.80 & 287.30 \\
\hline iii- $d-(F A+S L)+4^{*} S S C$ & 100.2 & 28806.66 & 287.49 \\
\hline iii- $d-S F-(E C R+S S C)+3^{*} S S C$ & 111 & 36636.71 & 309.39 \\
\hline$i v-d-S F+(E C R+S S C)+3^{*} S S C$ & 114.3 & 28781.50 & 310.35 \\
\hline$i v-c-(F A+S L)+(E C R+E C C)+4^{*} E C C$ & 103.9 & 44205.39 & 320.74 \\
\hline $\mathrm{iii}-\mathrm{C}-(\mathrm{FA}+\mathrm{SL})+(\mathrm{ECR}+\mathrm{SSC})+3^{*} \mathrm{SSC}$ & 110.7 & 34249.86 & 322.95 \\
\hline iii- $c-(F A+S L)+(E C R+E C C)+4^{\star} E C C$ & 100.7 & 43105.86 & 325.57 \\
\hline iii- $d-(E C R+S S C)+3^{*} S S C$ & 104.1 & 34610.87 & 332.48 \\
\hline iii- $d-\mathrm{FA} / \mathrm{SL}-(\mathrm{ECR}+\mathrm{SSC})+3^{*} \mathrm{SSC}$ & 106.9 & 34287.41 & 336.42 \\
\hline iii-c $-(E C R+S S C)+4^{*} S S C$ & 113.8 & 38471.87 & 338.07 \\
\hline iii-c $-F A / S L-(E C R+S S C)+3^{*} S S C$ & 100.9 & 34287.41 & 339.82 \\
\hline iii- $c-(F A+S L)+E C R+4^{*} S S C$ & 110.7 & 38110.86 & 344.27 \\
\hline
\end{tabular}

Table 4. Carbon emission of schemes.

\begin{tabular}{|c|c|c|c|c|}
\hline \multirow[b]{2}{*}{ Schemes } & \multicolumn{4}{|c|}{ Carbon emission } \\
\hline & Concrete $(t)$ & Reinforcement $(t)$ & Total $(t)$ & Unit emission $\left(t / m^{3}\right)$ \\
\hline $\mathrm{iii}-d-(\mathrm{FA}+\mathrm{SL})+4^{*} \mathrm{SSC}$ & 7.45 & 4.90 & \multirow{4}{*}{12.38} & \multirow{4}{*}{0.425} \\
\hline $\mathrm{iii}-C-(F A+S L)+(E C R+S S C)+3^{*} S S C$ & 7.45 & 4.90 & & \\
\hline $\mathrm{iii}-\mathrm{C}-(\mathrm{FA}+\mathrm{SL})+(\mathrm{ECR}+\mathrm{ECC})+4^{*} \mathrm{ECC}$ & 7.45 & 4.90 & & \\
\hline $\mathrm{iii}-c-(F A+S L)+E C R+4^{*} S S C$ & 7.45 & 4.90 & & \\
\hline iv- $d-(F A+S L)-4 * S S C$ & 8.24 & 4.25 & \multirow{2}{*}{12.49} & \multirow{2}{*}{0.429} \\
\hline$i v-c-(F A+S L)+(E C R+E C C)+4^{*} E C C$ & 8.24 & 4.25 & & \\
\hline iii- $d-\mathrm{FA} / \mathrm{SL}-(\mathrm{ECR}+\mathrm{SSC})+3^{*} \mathrm{SSC}$ & 12.05 & 4.90 & \multirow{2}{*}{16.95} & \multirow{2}{*}{0.582} \\
\hline iii-c $-F A / S L-(E C R+S S C)+3^{*} S S C$ & 12.05 & 4.90 & & \\
\hline $\mathrm{iv}-d-\mathrm{FA} / \mathrm{SL}+(\mathrm{ECR}+\mathrm{SSC})+3^{*} \mathrm{SSC}$ & 13.14 & 4.25 & 17.40 & 0.598 \\
\hline iii- $d-S F-(E C R+S S C)+3^{*} S S C$ & 15.68 & 4.90 & 20.58 & 0.707 \\
\hline $\mathrm{iii}-d-(\mathrm{ECR}+\mathrm{SSC})+3^{*} \mathrm{SSC}$ & 16.59 & 4.90 & \multirow{2}{*}{21.49} & \multirow{2}{*}{0.738} \\
\hline $\mathrm{iii}-C-(E C R+S S C)+4^{*} S S C$ & 16.59 & 4.90 & & \\
\hline $\mathrm{iv}-d-\mathrm{SF}+(\mathrm{ECR}+\mathrm{SSC})+3^{*} \mathrm{SSC}$ & 17.40 & 4.25 & 21.66 & 0.744 \\
\hline
\end{tabular}

As can be seen from the results above, the carbon emission of concrete is the dominant part in that of the concrete component, which varies from 60 to $80 \%$. Meanwhile, concrete with more cement replacement admixtures shows better environmental property than plain concrete, and the schemes with highest replacement rate show lowest carbon emission from concrete, which gives more advantage to the mineral admixtures.

For the convenience of comparison between different schemes or different components, a common basis should be settled. For residential structures, carbon emission on unit building area is quite common. While for bridge structures, emission for unit component volume is more convenient.
If the users and owners favour the schemes with unit emission lower than $0.5 \mathrm{t} / \mathrm{m}^{3}$, only nine schemes left could meet the requirement.

\subsection{Level 5}

The user-friendly design requires not only the safety and reliability of bridge structure, which ensures customer's personal and property security, but also the delicate design of bridge deck system, which creates cosy atmosphere for driving. The bridge deck pavement should employ soundabsorbing material to lower the level of noise and environmental-friendly material so as not to emit unfavourable gas or dust. The overall design scheme should also cater to the convenience of 
servicemen, maintainers, testers, and other working personnel (Paul \& Taylor, 2008).

User-friendly design does not raise quantitative clauses, but more of qualitative requirements, which gives designers guidance instead of strict rules.

\section{CONCLUSION}

The LCD is a multi-objective and multi-criteria designing system, in which full aspects of structures are involved, including the safety and reliability design, durability design, economic assessment, environmental assessment, and the evaluation from users and society. In order to settle an adequate clue and order for the LCD, the design objectives and criteria are arranged into five levels.

In the safety and reliability design stage, structural form, level of concrete and reinforcement, and thickness of concrete cover are taken as the design variables, whose various combinations make abundant design schemes.

When the structural durability is concerned, mineral admixtures and durability techniques are required. Results show that using mineral admixtures is the most convenient and effective way to promote concrete structures' durability and the painting of organic coatings on reinforcement and concrete surface also shows favorable effects. The electrochemical techniques provide the best durable effects among all, which could double or triple the durability lifetime.

The LCC assessment mainly discusses the direct and indirect costs of various durability measures. It turns out that the direct cost of electrochemical methods is much higher than that of admixtures and coatings, which leaves the ECE and BE few advantages for competition. And the operation of electrochemical measures requires regional traffic control or limitation, which would cost even higher indirect cost. Thus, the mineral admixtures and organic coatings have advantages on both direct and indirect costs.

Carbon emission is taken as the major index of environmental assessment, which, in the case of a bridge component, concerns mainly the construction stage. The main sources of carbon emission are the consumption of concrete and reinforcement. And it is obvious that the schemes with higher cement replacement rate would have better environmental assessment.

The evaluation from users and society mainly focuses on the entire structure, rather than one component, as in our case the cap beam.

The schemes left qualified are those with variable crosssection (II), higher reinforcement level (HRB500), and mostly with combined admixtures and large cement replacement rate. Organic coatings, such as epoxy coating and saline soakage, are operated repeatedly to keep the serviceability of concrete, and the epoxy coating for reinforcement is also favorable.

\section{ACKNOWLEDGMENT}

The research work was supported by project from Science and Technology Department of Zhejiang Province (2015C33005).

\section{REFERENCES}

Alting, L. (1995). Life cycle engineering and design. CIRP Annals-Manufacturing Technology, 44(2), 569-580.

Basbagill, J., Flager, F., Lepech, M., \& Fischer, M. (2013). Application of life-cycle assessment to early stage building design for reduced embodied environmental impacts. Building and Environment, 60, 81-92.

Bergmeister, K. (2014). Life-cycle design for the world's longest tunnel project. Aquananotechnology: Global prospects (p. 35).

Biondini, F., \& Frangopol, D. M. (2014). Life-cycle performance of structural systems under uncertainty. Structures congress 2014 (pp. 2233-2244). ASCE.

CCES 01-2004. (2004). Guide to durability design and construction of concrete structures.

Chen, J. H., Su, Z. M., \& Li, D. Z. (2009). Quantitative evaluation of Life-cycle energy consumption of residential building. $11^{\text {th }}$ Chinese journal of management science academic annual meeting. Chengdu, China: CJMS Press.

Cho, H. N., Kim, J. H., Choi, Y. M., \& Lee, K. M. (2003). Practical application of life-cycle cost effective design and rehabilitation of civil infrastructures. 3th International Workshop on Life-Cycle Cost Analysis and Design of Civil Infrastructure Systems.

Frangopol, D. M., Kong, J. S., \& Gharaibeh, E. S. (2001). Reliability-based life-cycle management of highway bridges. Journal of Computing in Civil Engineering, 15(1), 27-34.

Furuta, H., Kameda, T., Nakahara, K., Takahashi, Y., \& Frangopol, D. M. (2006). Optimal bridge maintenance planning using improved multiobjective genetic algorithm. Structure and Infrastructure Engineering, 2(1), 33-41.

Hassan, N. M., Al Maazmi, T., Al Hadhrami, A., \& Al Hosani, M. (2015). Discrete event simulation: A vital tool for a concurrent life cycle design. Construction Innovation, 16(1).

$\mathrm{Hu}, \mathrm{Q}$. Z. (2009). Key indicators of design theory on engineering structures in whole life-cycle. Hangzhou, China: Zhejiang University. 
Institute for Building Environment and Energy Conservation. (2014). Comprehensive assessment system for built environment efficiency.

Ishii, K. (1995). Life-cycle engineering design. Journal of Vibration and Acoustics, 117(B), 42-47.

Jin, W. L., \& Zhong, X. P. (2012). Life-cycle design theoretical system of sustainable engineering structures. Engineering Sciences.

Kim, S. J., Kara, S., \& Kayis, B. (2014). Economic and environmental assessment of product life cycle design: Volume and technology perspective. Journal of Cleaner Production, 75, 75-85.

Kota, S., \& Chakrabarti, A. (2014). ACLODS: A holistic framework for product life cycle design. International Journal of Product Development 20, 19(1-3), 90-112.

Liu, Q. B., \& Zhou, R. Q. (2003). Research of synthetic assessment target system in green residential quarters. New Architecture.

Lu, B., Gu, P., \& Spiewak, S. (2011). Integrated life cycle design approach for sustainable product development. Proceedings of the Canadian Engineering Education Association.

Mora, R., Bitsuamlak, G., \& Horvat, M. (2011). Integrated life-cycle design of building enclosures. Building and Environment, 46(7), 1469-1479.
Paul, W. L., \& Taylor, P. A. (2008). A comparison of occupant comfort and satisfaction between a green building and a conventional building. Building and Environment, 43(11), 1858-1870.

Ramani, K., Ramanujan, D., Bernstein, W. Z., Zhao, F., Sutherland, J., Handwerker, C., ... Thurston, D. (2010). Integrated sustainable life cycle design: A review. Journal of Mechanical Design, 132(9), 091004.

Roper, K. O., \& Beard, J. L. (2006). Justifying sustainable buildings-championing green operations. Journal of Corporate Real Estate, 8(2), 91-103.

SD5075-1.0:2013. (2014). Code for a sustainable built environment, BREEAM international new construction - Technical manual. BRE Global.

Teplý, B., Vořechovská, D., \& Keršner, Z. (2010). Performance-based design of concrete structures: Durability aspects. Structural Engineering and Mechanics, 35(4), 535-538.

US Green Building Council. (2000). Leadership in energy and environmental design - Green building rating system. Author.

Zhong, X. P., \& Jin, W. L. (2009). Research on design framework of engineering structure in whole lifecycle. Proc. 11th CAST annual conference on independent innovation and sustainable growth (2) Chongqing, China: CAST Press. 